\title{
Entrevista com David Bartram
}

\author{
Interview with David Bartram
}

\section{Gustavo Taniguti $^{\mathrm{a}}$}

\section{Traduzido por Nara Nília Marques Nogueira}

Nesta entrevista, convidamos o professor David Bartram a refletir sobre o tema das migrações no mundo contemporâneo em sintonia com alguns de seus trabalhos recentes. Bartram é Professor da Universidade de Leicester, Reino Unido e Coordenador do Programa do Comitê de Pesquisa em Sociologia das Migrações (RC31) da Associação Sociológica Internacional (ISA). A realização do Fórum de Sociologia da ISA em Porto Alegre em fevereiro de 2021 tornou oportuna a realização dessa entrevista.

Revista Plural Em um estudo recente, você discute a sociabilidade dos migrantes recém-chegados à Europa questionando a noção de "conectividade diminuída" que, no senso comum, supostamente acompanha o movimento migratório. Você poderia descrever seu argumento a esse respeito?

David Bartram A principal descoberta desse estudo é que a migração às vezes leva a um "aumento" na quantidade e na qualidade das conexões sociais dos migrantes. A maioria das pesquisas existentes nessa área conclui que há uma diminuição. Isso não surpreende - a migração pode desestabilizar os laços sociais e pode haver desafios para a formação de novos laços no país de destino. Mas a pesquisa que explora essa questão tem sido totalmente qualitativa - valiosa por sua profundidade, é claro, mas também limitada no escopo (e.g. geograficamente). O artigo que publiquei (na Sociological Research Online) ${ }^{1}$ é o primeiro estudo quantitativo que conheço sobre esse tópico, usando dados da Pesquisa Social Europeia. O que esse fato demonstra é que o quadro da pesquisa qualitativa é incompleto; reafirmo que, por vezes, a sociabilidade entre migrantes aumenta, mesmo logo após sua chegada. O padrão aparente é que, se alguém emigra de uma sociedade em que as pessoas em geral têm menos laços sociais e se muda para uma socie-

a Professor visitante no Instituto Federal de Minas Gerais (IF-MG) e-mail: gustavotaniguti@gmail.com ORCID: https://orcid.org/oooo-0003-3905-5140

1 BARTRAM, 2019. 
dade em que as conexões sociais são mais difundidas, é provável que sua sociabilidade aumente. Esse cenário se aplica especialmente às pessoas que emigram da Turquia e da Hungria. (O inverso também é verdadeiro.)

Revista Plural Na sua opinião, como a sociabilidade dos migrantes difere da noção de capital social e laços sociais (os últimos que, desde os estudos de Mark Granovetter, são considerados uma fonte estratégica para se conseguir um emprego)? David Bartram O que tenho em mente é simplesmente a experiência de sentir-se conectado a outras pessoas. O conceito de "capital social" tem mais a ver com a maneira como as conexões podem levar a melhores resultados econômicos - empregos, especialmente. A perspectiva do trabalho é obviamente importante para os migrantes - mas também é importante que eles simplesmente tenham conexões sociais para seu próprio bem, pela qualidade de vida de uma pessoa, de forma mais direta.

Revista Plural Considerando os eventos políticos em andamento no Reino Unido, como o Brexit poderia impactar os processos de cidadania dos migrantes?

David Bartram O processo de conquista da cidadania no Reino Unido tem sido significativamente distorcido pelo Brexit e pelos acontecimentos sociais que levaram ao Brexit. O Reino Unido já possuía uma relação conturbada com a questão da imigração, que remonta ao período do Império. Em um âmbito institucional, nunca foi desejado que houvesse imigração das ex-colônias - menos ainda se os indivíduos não fossem brancos. O Brexit vem à tona, em parte, devido ao fracasso da Grã-Bretanha em se reconciliar com esse legado. A ansiedade acerca da imigração não é o único fator que leva ao resultado do referendo (nunca se esqueça de que as trapaças às leis de financiamento eleitoral provavelmente impulsionaram o voto pela saída ultrapassar os 50\%) - mas permitiu que as forças de direita pressionassem uma política mais rígida contra os imigrantes da Europa, de uma maneira que não era possível para imigrantes estabelecidos da "Nova Commonwealth".

O Escândalo Windrush é uma extensão inevitável dessa reação. Milhares de imigrantes que chegaram nos anos 1950 e 1960 foram mal identificados como “imigrantes ilegais" não porque não são realmente cidadãos, mas porque não possuem a documentação atualmente aceita para estabelecer cidadania. Do ponto de vista administrativo, a xenofobia inspirada pelo Brexit dirigida contra os europeus questionou a cidadania de pessoas que estão aqui há décadas - e esse impacto atinge exclusivamente pessoas não brancas. 
Revista Plural Na sua opinião, de que maneira os processos de cidadania britânica diferem de outros países europeus que recebem imigrantes?

David Bartram A primeira coisa a se dizer é que há muitas coincidências no que tange aos processos de cidadania do Reino Unido e da Europa (continental). Outros países europeus têm algumas semelhanças em processos históricos que levam à imigração - em particular, uma história colonial. Por exemplo, a experiência da França com a Argélia tem muito em comum com o regime da "comunidade britânica": os argelinos eram cidadãos franceses da mesma maneira que os jamaicanos costumavam ser cidadãos do Reino Unido (ou "nacionais"), com ambos os grupos tirando vantagem de seu direito de migrar em uma direção que contrariava a lógica colonial original. O "desconforto" produzido por essa migração levou, em ambos os casos, a noções mais restritas de cidadania.

Atualmente, alguns países europeus exigem um teste de cidadania como condição para naturalização que se assemelha ao teste britânico "Life in the UK" (também necessário para obter uma autorização de residência permanente). Uma observação comum sobre esses testes é que eles funcionam mais como barreiras à cidadania do que como mecanismos de integração. Uma razão para essa observação é que eles geralmente exigem que os imigrantes saibam coisas (por exemplo, curiosidades históricas) que a maioria dos cidadãos "nativos" não saberia. Esse tipo de requisito se torna mais fácil de entender quando reconhecemos uma importante percepção de Anne-Marie Fortier: a política de teste não visa o grupo-alvo óbvio (imigrantes), mas sim a população "nativa", especialmente aqueles que estão ansiosos com a imigração. A política procura acalmar os medos destes, assegurando-lhes que o governo está "fazendo algo" a respeito da imigração.

Novamente, nesse aspecto, o processo de cidadania do Reino Unido não é diferente do de outros países europeus. O que diferencia o Reino Unido nos dias atuais é a maneira como a cidadania nacional no Reino Unido está se distanciando da cidadania europeia. Essencialmente, quando um cidadão de um país da UE mora em outro país da UE, não ter cidadania nacional no país de residência não equivale a ser um “estrangeiro”. Um belga que mora na França não sente grande insegurança por não ter cidadania francesa.

O mesmo não mais se aplica aos cidadãos da UE que vivem no Reino Unido; a experiência do Brexit transformou-os em "estrangeiros" de uma maneira incomparável e exacerbou dramaticamente sua insegurança. Vemos, assim, uma consequência não intencional: alguns cidadãos da UE deram entrada em processos de naturalização no Reino Unido não porque de repente se sintam mais britânicos, mas precisamente porque foram rejeitados pela Grã-Bretanha. Ao mesmo tempo, 
muitos cidadãos britânicos estão solicitando a cidadania em outros países da UE, mesmo que nunca tenham morado lá, nem planejem fazê-lo. O maior exemplo pertence à Irlanda; centenas de milhares (senão milhões) de cidadãos do Reino Unido são elegíveis para a cidadania irlandesa e alguns se inscreveram para obtê-la simplesmente para preservar seu direito à liberdade de circulação na UE. Nos dois casos, o Brexit enfraqueceu, assim, os laços com a Grã-Bretanha sentidos por algumas das pessoas que moram aqui.

Revista Plural O Pacto Global para Migração Segura, Ordenada e Regular (GCM) foi assinado em dezembro de 2018, em Marrakesh, Marrocos, como um acordo negociado intergovernamentalmente, cobrindo várias dimensões da migração internacional, preparado sob os auspícios das Nações Unidas. Ao mesmo tempo que o acordo intenciona melhorar a governança global da migração, algumas nações preferiram desenvolver políticas de migração unilaterais. Curiosamente, algumas delas são ex-colônias cuja população era composta por migrantes, como é o caso dos Estados Unidos e do Brasil. É possível afirmar que as políticas de migração estão sujeitas a invariáveis vicissitudes políticas?

David Bartram Certamente é verdade que as vicissitudes políticas são uma característica eterna da conjuntura política que envolve as políticas de migração. O GCM é, obviamente, uma iniciativa louvável - mas seu impacto na formulação de políticas em nível nacional é limitado, sobretudo porque é um acordo não vinculativo. Como já esperado, um princípio básico é o respeito pela soberania nacional; sem esse princípio, muitos países nunca o teriam assinado (e, é claro, os EUA e alguns outros países votaram contra o pacto). O GCM é altamente válido ele é uma estrutura para o desenvolvimento de novas iniciativas que (esperamos) trarão benefícios tangíveis -, contudo possui um potencial limitado para superar tendências contrárias em países que não estão comprometidos com a cooperação internacional nessa esfera.

A pesquisa e o ensino realizados nas últimas décadas por estudiosos da migração contribuíram com o surgimento de um entendimento mais humano e matizado sobre a migração. Infelizmente, porém, essa tendência não é irreversível; há uma necessidade contínua de confrontar as forças políticas que tentam capitalizar em torno de um potencial latente para a xenofobia. O GCM é realmente útil nesse sentido.

Revista Plural No seu trabalho, você desenvolve a abordagem de 'felicidade' para avançar no estudo da migração internacional. Você poderia nos contar mais sobre isso? Por que a 'felicidade' é importante para o estudo dos migrantes? 
David Bartram A felicidade é importante para os imigrantes da mesma maneira que é importante para a maioria das pessoas. A felicidade é útil como um contraponto aos aspectos "objetivos" da vida das pessoas (sua situação econômica, seu emprego, suas conexões sociais, etc.). O estudo da felicidade questiona: qual é a relação entre essas circunstâncias objetivas e a maneira como as pessoas se sentem sobre suas vidas? Talvez seja fácil demais supor que a migração (especialmente para um país mais rico) melhore a vida das pessoas. Melhorias objetivas são importantes mas não devemos presumir que as melhorias específicas que percebemos como estudiosos / observadores realmente fazem os migrantes se sentirem mais felizes no país de destino. Talvez os migrantes às vezes sejam excessivamente otimistas sobre o que alcançarão com a migração, ou talvez às vezes descubram que os objetivos que perseguiram se revelam menos importantes do que haviam pensado.

O estudo da felicidade entre os migrantes é útil para explorar lacunas desse tipo. Por exemplo: um objetivo claro de alguns migrantes é melhorar sua situação econômica, aumentar sua renda. Mudar para um país mais rico pode certamente aumentar a renda de uma pessoa em um sentido absoluto (ou seja, comparando com a renda no país de origem). Mas também pode diminuir sua renda "relativa", comparada à situação de outras pessoas no país de destino. Os estudos sobre felicidade sugerem que a renda relativa é mais importante que a renda absoluta para a felicidade - portanto, a migração pode trazer uma diminuição da felicidade, pelo menos nesse aspecto.

Muitas pessoas fazem escolhas baseadas em previsões otimistas (que minimizam o risco de resultados negativos ou indesejados). Em alguns casos, a migração pode se encaixar nessa descrição. Obviamente, uma visão geral desse tipo é apenas um ponto de partida; o que é especialmente interessante é explorar as situações que levam a resultados com os quais os migrantes estão satisfeitos e depois compará-las com resultados menos favoráveis.

Revista Plural Você é o atual coordenador do programa do Comitê de Pesquisa em Sociologia das Migrações (RC31) da Associação Sociológica Internacional. No próximo Fórum de Sociologia da ISA, a ser realizado em Porto Alegre, no Brasil, haverá 20 sessões temáticas e 5 mesas-redondas sobre imigração. Qual a importância de ter um fórum de discussão global dedicado ao debate sociológico sobre migração?

David Bartram A singularidade da ISA consiste na maneira como reúne estudiosos de uma vasta gama de formações intelectuais. A migração é um fenômeno global - mas é vivenciada de maneira diferente em contextos diferentes, e a maneira 
como os cientistas sociais a investigam depende, em parte, das diferentes tradições intelectuais que sustentam seu trabalho. Podemos aprender um com o outro explorando essa diversidade; podemos obter informações sobre nossas próprias suposições e descobertas, considerando a forma como outra pessoa pode ver nosso trabalho. Essa é uma tarefa desafiadora - mas também altamente gratificante.

Revista Plural O interesse da ISA no estudo da migração remonta ao seu primeiro congresso, realizado em Zurique, em 1950. Nesse mesmo ano, o sociólogo brasileiro Fernando de Azevedo foi eleito vice-presidente da ISA. Naquela década, o Brasil era visto como uma sociedade modelo para a integração de imigrantes, como apontado pelo sociólogo britânico Bertram Hutchinson. Todavia, pelo menos no Brasil, a história desse campo científico ainda é pouco examinada. Na sua opinião, qual é a importância de trazer de volta a história dos estudos sobre migração no campo da Sociologia?

David Bartram O estudo da migração é central para a disciplina da Sociologia. Quando estou lecionando para os alunos do primeiro ano da minha universidade, enfatizo a necessidade de definir a sociedade que nos propusemos a estudar via Sociologia: se dizemos que queremos estudar a "sociedade", precisamos perguntar - qual sociedade? Quais são seus limites e seu caráter? Quem são seus membros? Para a maioria das sociedades, não podemos responder a essa pergunta efetivamente sem investigar a imigração. É produtivo ajudar os alunos a identificar e criticar uma suposição que normalmente não é dita na vida cotidiana - a ideia de que qualquer "sociedade" é naturalmente uma entidade nacional, com membros óbvios. Dada a importância da imigração na maioria dos países, pode-se aprender muito sobre a própria sociedade, considerando a história e o estado atual da imigração - as pessoas que chegam, as políticas que governam sua entrada e integração, os acontecimentos sociais que às vezes são contra políticas, etc. Qualquer empreendimento sociológico que negligencie essas considerações sofre limitações desnecessárias.

\section{REFERÊNCIAS BIBLIOGRÁFICAS}

BARTRAM, David. (2019). Sociability among European Migrants. Sociological Research Online. 24. 136078041882321. https://doi.org/10.1177/1360780418823213. Acesso em: 06 abr. 2020.

Recebido: 11/10/2019 | Aprovado: 30/03/2020 